\title{
Congenital colonic atresia: 4 case reports
}

\begin{abstract}
Introduction: Colonic atresia is a rare cause of neonatal bowel obstruction. Choosing between intestinaldiversionand primary anastomosis for themanagement of this atresiaisstilldiscussed. Methods and results: We reviewed all cases of colonic atresia managed in our center between 2000 and 2012. We have recorded, summarized and analyzed clinical features, associated anomalies, location and type of atresia, management and outcome. We collected four cases of colonic atresia handled in our department during this period, one case of type I and three cases of type III according to the Grosfeld classification. Three of the cases had at least one-associated anomaly. Initial restoration of bowel continuity with a protective diversion was performed in one case, Delayed anastomosis following a primary intestinal diversion was performed in two cases, and primary anastomosis was performed in a one case. Death occurred in one case following a post-operative sepsis. Conclusion: Atresia of the colon is a rare etiology of the neonatal bowel obstruction. Colonic atresia can be associated with other congenital anomalies, which affect the prognosis. The prognosis of Colonic atresia in absence of other serious associations is good if proper management is carried out, with an overall mortality of $10 \%$.
\end{abstract}

Volume I Issue $3-2014$

\author{
Chouikh T, 1,2 Charieg A, ${ }^{1,2}$ Mrad C, ${ }^{2}$ Ghorbel \\ S, ${ }^{1,2}$ Saada S, ${ }^{3}$ Benkhalifa S, ${ }^{2,3}$ Jlidi $S^{1,2}$ \\ 'Tunis School of Medecine, University of Tunis El Manar, Tunisia \\ ${ }^{2}$ Department of Pediatric Surgery Tunis Children Hospital, \\ Tunisia \\ ${ }^{3}$ Department of Anesthesia-Reanimation, Tunis Children \\ Hospital,Tunisia
}

\section{Correspondence: Chouikh T,Tunis School of Medicine, University of Tunis El Manar, B.P. $n^{\circ}$ 94-Rommana 1068, Tunisia, Tel21623159436,Email agdal23@yahoo.fr}

Received: May 14, 2014 | Published: July 15, 2014

Keywords: neonatal occlusion, colonic atresia, newborn; surgery

\section{Introduction}

Colonic atresia is an uncommon cause of neonatal intestinal obstruction accounting for $1.8 \%$ to $15 \%$ of all gastrointestinal atresia. ${ }^{1}$ Binninger reported the first case of colonic atresia in $1673 .{ }^{2}$ Gaub reported the first survivor in 1922, an infant with sigmoid atresia who was treated with delayed colo colic anastomosis after a primary colostomy. Potts ${ }^{3}$ reported in 1947 the first survivor with an atresia of the transverse colon who was managed with a primary anastomosis. We performed a retrospective analysis of four cases handled in the department of pediatric surgery B of the children hospital of Tunis. The aim of this study is to acquire and present more detailed information about colonic atresia.

\section{Patients}

We searched for all cases of colonic atresia managed in our department from January 2000 to December 2012. Four cases were identified. Family and maternal history were unremarkable in all cases, and prenatal examinations were normal.

\section{Case I}

A girl weighing $3,050 \mathrm{Kg}$ was delivered with a gestational age of 41 week. At the 2 nd day of life she was admitted for neonatal occlusion with abdominal distension, bilious vomiting, and failure to pass meconium. Physical examination revealed a distended abdomen, no associated anomalies was founded. Abdominal X-Ray showed distended bowel, air fluid levels, with no air in the rectum (Figure 1). Surgical exploration was indicated and revealed a total colonic atresia (Type III) located at $3 \mathrm{~cm}$ below the Bauhin's valve (Figure 2). Colostomy was made with proximal colic biopsy that indicate normal colic segment with presence of neuroganglionnary cells, colic continuity was restored 6months later with resection of a segment of the proximal dilated colon, with uneventful follow up.

\section{Case 2}

A $3,300 \mathrm{Kg}$ boy was delivered after full term pregnancy; he was admitted in our department 48 hours after birth for neonatal occlusion. Physical examination revealed abdominal distension, abdominal X-ray showed distended bowel and air fluid level. Watersoluble contrast enema showed distal microcolon with an interruption of the colic continuity (Figure 3). Surgical exploration revealed type I colonic atresia, located at $10 \mathrm{~cm}$ below the Bauhin's valve, primary colic anastomosis with protective intestinal diversion were performed. The colostomy was closed 5 months later. Seven months later, the patient was readmitted for cholestatic jaundice, abdominal ultrasound showed dilated intra hepatic biliary ducts. An MRI with cholangiography showed a distended principal biliary duct with a free stone gallbladder. Surgical exploration for choledochal cyst was indicated and Bilio Intestinal anastomosis was performed after resection of the cyst, with uneventful follow up.

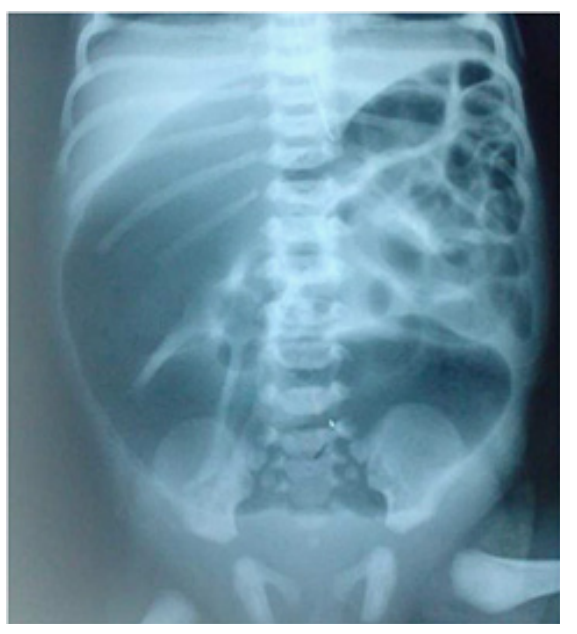

Figure I Abdominal films with distended bowel.

\section{Case 3}

A $2,050 \mathrm{Kg}$ girl was was delivered after a full term pregnancy, on her first day of life she was admitted for neonatal occlusion Clinical examination showed torticollis with a limb malformation. Abdominal X-Ray showed air fluid levels, Water-soluble contrast enema showed distal microcolon with an interruption of the opacification in the colon 
at the middle of the transverse colon. Surgical exploration found a type III colonic atresia of the transverse colon with no associated abnormalities. Operative correction by a primary anastomosis between the two parts of the transverse colon was made. Post operatively, intestinal transit was restored five days after surgery, the newborn developed after surgery respiratory distress due to an inhalation syndrome and death occurred two months later.

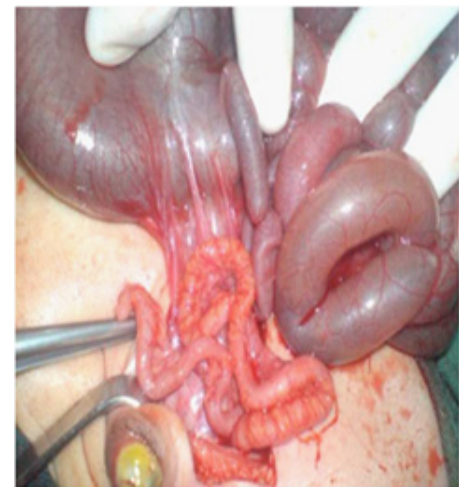

Figure 2 Type III colonic atresia below the Bauhin's valve.

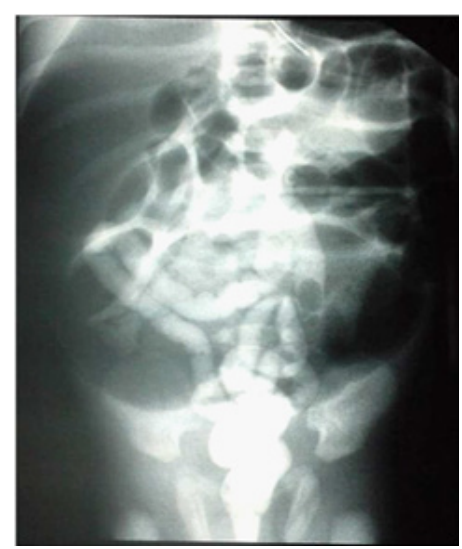

Figure 3 Water-soluble contrast enema showed distal microcolon with an interruption of the colonic continuity.

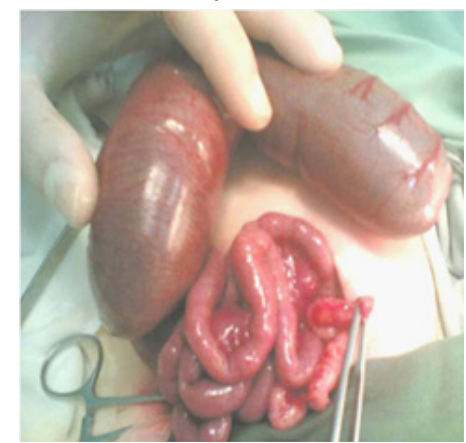

Figure 4 Type III colonic atresia of the transverse and left colon.

\section{Case 4}

A $2,080 \mathrm{Kg}$ girl was delivered after a normal gestation. 3 days after birth she was admitted for neonatal occlusion. Physical examination and abdominal X ray showed bowel, Surgical exploration revealed a type III colonic atresia of the transverse and left colon (Figure 4), Primary intestinal diversion was performed. The patient was discharged 9 days after the intervention. Restoration of colic continuity was performed 12 months later by an elective colo-colic anastomosis, 5 days later appeared abdominal distention with no stool emission, re intervention was then indicated, no leakage or anastomosis fistula was found. An intestinal diversion was performed. Histopathology results of intestinal biopsy showed absence of neuroganglionnary cells and concluded to an extended colic form of Hirschsprung disease. Duhamel pull through was performed with resection of the aganglionosis segment. Follow up was uneventful and the patient is now 6 years old with normal feeding and transit. The type of atresia was determined according to the classification of Grosfeld et al., ${ }^{4,5}$ (Figure 5).

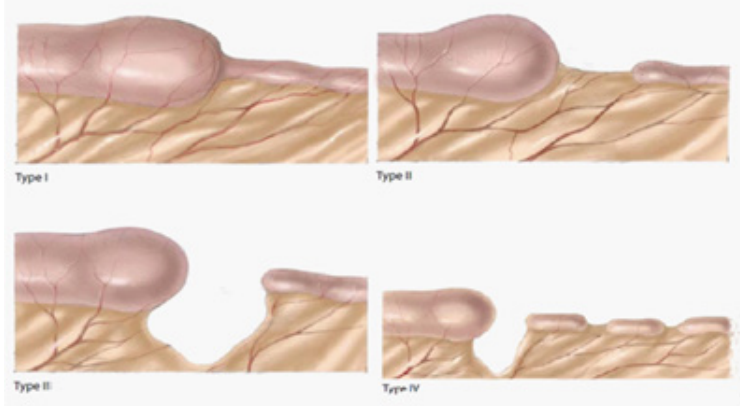

a. Type I is represented by a transluminal membrane or short atretic segment causing complete intestinal bowel obstruction, such as one of our cases.

b. Type II has the blind ending proximal bowel attached to the collapsed and undelveloped distal bowel by a fibrous cord along the edge of mesentery. There is no mesenteric defect.

c. Type III is similar to type II except that the fibrous connecting cord is absent and there is a V-shaped meseneteric defect, such as 3 cases of our study.

d. Type IV represents multiple segment atresias like a string of sausages or a combination of types I and III (Table I).

Figure 5 Grosfeld classification for intestinal atresia.

\section{Discussion}

Atresia of the colon is one of the rarest intestinal atresia. There are several theories that attempt to explain the etiology of colonic atresia, the main one concerns the intra- uterine extrinsic mesenteric vascular obstruction, which can be caused by an internal hernia, a volvulus, an intussusception, or a strangulation in tight gastroschisis. ${ }^{3,-9}$ Association between colonic atresia and choledochal cyst as mentioned in one of our cases, has been reported, colonic atresia is due in these cases to an intrauterine direct pressure effect of the cyst on the transverse colon mesentery. ${ }^{10}$ Intraluminal vascular factors have also been reported as an etiology of colonic atresia, Erskine proposed the possibility of emboli originating from the placenta and reaching the mesenteric circulation by bypassing the pulmonary circulation. ${ }^{11}$ Fetal infection with varicella has also been described as one of the causes of colonic atresia, ${ }^{12-14}$ injury of the enteric plexus by varicella may lead to poor vessel development and induce ischemic conditions resulting into colonic atresia.

Familial cases of colonic atresia have been reported, ${ }^{15}$ but most of the reports were lacking detailed family histories. The incidence of associated anomalies in cases of colonic atresia is lower than the other intestinal atresia, however colonic atresia may be associated with various congenital anomalies, like abdominal wall defects such in gastroschisis where the intrauterine closure of gastroschisis around a segment of mid-gut may be an overlooked cause of isolated colonic atresia. ${ }^{16}$ Other unusual associations reported were ophthalmic anomalies, bladder extrophy, exomphalos, vesico-intestinal fistula, as well as choledochal cyst. ${ }^{17}$ The association of colonic atresia and Hirschsprung's disease have been reported in 20 cases in literature ${ }^{18,19}$ we report in this article the 21th case of Hirschsprung's 
disease associated with colonic atresia. Literature has estimated that coexistent Hirschsprung's disease is present in $2 \%$ of patients with colonic atresia, ${ }^{20}$ incidence of simultaneous colonic atresia and Hirschsprung's disease is estimated to be 1 in 10 million live births. The mean age of the diagnostic of Hirschsprung's disease when associated with colonic atresia is 8 months (ranging from 1 week to 5years) ${ }^{21}$ and was 10 months in our case. Hirschsprung's disease is diagnosed after one or more unsuccessful procedures for atresia. After intestinal anastomosis, the child presented post-operative complications such as anastomotic dehiscence or functional intestinal obstruction requiring staged intestinal diversion followed by resection of aganglionic distal colon and a pull through procedure.

Newborns with colonic atresia present usual signs of distal bowel obstruction. Plain radiography of the abdomen reveals dilated bowel loops with air fluid levels; we can find a huge distended loop representing the colon proximal to the atretic segment. Water soluble contrast is helpful, but care must be taken because of the risk of distal colon perforation. In the type I of colonic atresia, a "wind sock sign" can be seen as the contrast pushes against the membrane, ${ }^{22-24}$ or Hook sign on the microcolon side of the colonic atresia in type III. ${ }^{25}$ Classical surgical approach was primary anastomosis in the right colonic atresia proximal to the splenic flexure and colostomy with delayed anastomosis for the other locations. ${ }^{1,25}$ Primary anastomosis or primary anastomosis with intestinal diversion depending on the condition of newborn is considered as an efficient approach for the management of colonic atresia. However, primary anastomosis may be technically difficult because of the very large difference between the sizes of the distal and proximal bowels, and the loss of length associated with resection of dilated proximal colon. ${ }^{26}$ Many authors have reported the resection and primary anastomosis as a reasonable treatment option regardless of the location of colonic atresia, if the newborn's condition allows it. ${ }^{27}$ Patency of the distal colon segment should be tested by retrograde or antegrade instillation of air and saline. Further management recommendations vary widely, proximal colostomy is well tolerated in infants and delayed reestablishment of intestinal continuity can be done later. The proximal and distal colonic ends adjacent to the atresia are abnormal in both innervation and vascularisation, that's why in addition to resecting the bulbous proximal end, a portion of the microcolon should also be resected. ${ }^{27}$

Rectal biopsy included in the initial surgical procedure seems to be an important step in the management of colonic atresia to avoid delayed diagnosis of Hirschsprung's disease and the appearance of complications. The morbidity and mortality depend on several factors such as delay in diagnosis and treatment, nutritional status, sepsis, or associated anomalies. ${ }^{2}$ Unlike atresia of the proximal small bowel, the diagnosis of colonic atresia is commonly delayed until feeding have been started ,then abdominal distension, fecaloid vomiting, and failure to pass meconium are noted. This delay results in more severe dehydration, sepsis, and higher mortality rate. ${ }^{28}$ In the absence of small bowel atresia, the normal length of small intestine should allow normal bowel function. ${ }^{2,25}$ If colonic atresia diagnosed early and if other major pathologies are absent, overall mortality should be $10 \%$ or less, ${ }^{27}$ early diagnosed and individually treated isolated cases of colonic atresia are not likely to have an unfavorable prognosis. Significant high mortality rates in cases operated after 72 hours seem to underline the importance of early diagnosis and treatment. The diagnosis of colonic atresia is still likely to be easily missed and the treatment be delayed. Early perinatal diagnosis and individualized operation are the key steps of the management of colonic atresia. ${ }^{18}$ Treatment should be adapted for each patient based on clinical status and associated anomalies to give optimal results with less morbidity (Table 1).

Table I Summary of the cases (surgical exploration and associated malformations)

\begin{tabular}{lllllll}
\hline Cases & $\begin{array}{l}\text { Gender/Age } \\
\text { (Hours) }\end{array}$ & Weight $(\mathbf{k g})$ & Type of Atresia & Associated Malformations & Initial Procedure & Evolution \\
\hline I & F/ 48 H & 3.050 & Type I & - & $\begin{array}{l}\text { Colostomy } \\
\text { Colic anastomosis } \\
\text { protective colostomy }\end{array}$ & Uneventful \\
2 & M/ 48 H & 2.050 & Type III (Figure 4) & Choledochal Cyst & Primary anastomosis & Death \\
3 & F/ 24 H & 3.300 & Type III & $\begin{array}{l}\text { Torticollis and limb } \\
\text { malformation }\end{array}$ & Colostomy & Uneventful \\
\hline
\end{tabular}

\section{Conclusion}

Atresia of the colon represents the least common cause of neonatal intestinal obstruction. The choice of the operative therapy in colonic atresia should be individualized, based on the condition of the patient and the presence of associated anomalies.

\section{Acknowledgments}

None.

\section{Conflicts of interest}

The authors have no conflict of interests related to this publication and have not received any grants.

\section{Funding}

None.

\section{References}

1. Freeman NV . Congenital atresia and stenosis of the colon. Br J Surg. 1966;53(7):595-599.
2. Powell RW, Raffensperger JG. Congenital colonic atresia. J Pediatr Surg. 1982;17(2):166-170.

3. Potts WJ. Congenital atresia of intestine and colon. Surg Gynec Obstet. 1947;85(1):14-19.

4. Grosfeld JL, Ballantine TV, Shoemaker R. Operative management of intestinal atresia and stenosis based on pathologic findings. J Pediatr Surg. 1979;14(3):368-375.

5. Millar AJW, Rode H. Jejuno ileal Atresia. In: Prem Puri, Michael E Hollwarth. Editors. Pediatric Surgery. Berlin, Germany: Springer Science \& Business Media; 2006. pp. 213-228.

6. Benson CD, Lotfi MW, Brogh AJ. Congenital atresia and stenosis of the colon. J Pediatr Surg. 1968;3(2):253-257.

7. Ogunyemi D. Gastroschisis complicated by midgut atresia, absorption of bowel, and closure of the abdominal wall defect. Fetal Diagn Ther. 2001;16(4):227-230.

8. Wang NL, Yeh ML, Chang PY, et al. Prenatal and neonatal intussusceptions. Pediatr Surg Int. 1998;13(4):232-236.

9. Black PR, Mueller D, Crow J, et al. Mesenteric defects as a cause of intestinal volvulus without malrotation and as the possible primary etiology of intestinal atresia. J Pediatr Surg. 1994;29(10):1339-1343. 
10. Al Wafi A, Morris Stiff G, Lari A (1998) Colonic atresia secondary to a choledochal cyst. Pediatr Surg Int. 1998;13(5-6):422-423.

11. Erskine JM.Colonic stenosis in the newborn:the possible thromboembolic etiology of intestinal stenosis and atresia. J Pediatr Surg. 1970;5(3):321-333.

12. Alexander. Congenital varicella. Br Med J. 1979;2(6197):1074.

13. Hitchcock R, Birthistle $\mathrm{K}$, Carrington D, et al. Colonic atresia and spinal cord atrophy associated with a case of fetal varicella syndrome. $J$ Pediatr Surg. 1995;30(9):1344-1347.

14. Alkalay AL, Pomerance JJ, Rimoin DL. Fetal varicella syndrome. $J$ Pediatr. 1987;111(3):320-323.

15. Guttman FM, Braun P, Garance PH, et al. Multiple atresias and a new syndrome of hereditary multiple atresias involving the gastrointestinal tract from stomach to rectum. J Pediatr Surg. 1973;8(5):633-640.

16. Anveden-Hertzberg L, Gauderer MW. Paraumbilical intestinal remnant, closed abdominal wall, and midgut loss in a neonate. J Pediatr Surg. 1996;31(6):862-863.

17. Powell RW, Raffensperger JG. Congenital colonic atresia. J Pediatr Surg. 1982;17(2):166-170.

18. Etensel B, Temir G, Karkiner A, et al. Atresia of the colon. J Pediatr Surg. 2005;4(8):1258-1268.

19. Draus JM, Maxfield CM, Bond SJ. Hirschsprung's disease in an infant with colonic atresia and normal fixation of the distal colon. $J$ Pediatr Surg. 2007;42(2):e5-e8.
20. Arca MJ, Oldham KT. Atresia, stenosis, and other obstructions of the colon. Pediatric Surgery. 7th edn. Amsterdam, The Netherlands: Elsevier; 2012. pp. 1247-1253.

21. Bley WR, Franken EA. Roentgenology of colon atresia. Pediat Radiol. 1973;1(2):105-108.

22. Blank E, Afshani E, Girdany BR, et al. "Windsock Sign" of congenital membranous atresia of the colon. Am J Roentgenol Radium Ther Nucl Med. 1974;120(2):330-332.

23. Blair GK, Jamieson DH. Colon atresia-type III. J Pediatr Surg. 2001;36(3):530-531.

24. Grosfeld JL, Ballantine TV, Shoemaker R. Operative management of intestinal atresia and stenosis based on pathologic findings. $J$ Pediatr Surg. 1979;14(3):368-375.

25. Boles ET, Vassy LE, Ralston M. Atresia of the colon. J Pediatr Surg. 1976;11(1):69-75.

26. Hsu CT, Wang SS, Houng JF, et al. Congenital colonic atresia:report of one Case. Pediatr Neonatol. 2010;51(3):186-189.

27. Pohlson EC, Hatch EI Jr, Glick PL, et al. Individualized management of colonic atresia. Am J Surg. 1988;155(5):690-692.

28. Karnak I, Ciftci AO, Senocak ME, et al. Colonic atresia: surgical management and outcome. Pediatr Surg Int. 2001;17(8):631-635. 